\title{
Loop-mediated Isothermal Amplification LAMP, Simple Alternative Technique of Molecular Diagnosis Process in Medicals Analysis: A Review
}

\author{
T. Uwiringiyeyezu ${ }^{1,2}$, B. El Khalfi ${ }^{1}$, J. Belhachmi ${ }^{2}$ and A. Soukri ${ }^{1^{*}}$ \\ ${ }^{1}$ Laboratory of Physiopathology, Molecular Genetic and Biotechnology, Faculty of Sciences Aïn \\ Chock, University Hassan II of Casablanca, Morocco. \\ ${ }^{2}$ Laboratory Al Kindy of Medicals Analysis, Casablanca, Morocco.
}

Authors' contributions

This work is a part of PhD degree preparation; it is carried out in collaboration between both authors in an equal work in realizing the review, draft writing and correction. They also wrote, read and

approved the definitive manuscript.

Article Information

DOI: 10.9734/ARRB/2019/v33i130109

Editor(s):

(1) Dr. Bechan Sharma, Department of Biochemistry, University of Allahabad, Allahabad, India.

Reviewers:

(1) Panan Kanchanaphhum, Rangsit University, Thailand.

(2) Keith J. Stine, University of Missouri, USA.

Complete Peer review History: http://www.sdiarticle3.com/review-history/50826

Review Article

Received 27 June 2019

Accepted 29 August 2019

Published 09 September 2019

\begin{abstract}
The Medical diagnostic process requires more various methods to cover all sorts of clinical demands. Those methods depend on the types of samples and the requested analysis. The Medical diagnostic is considered as a process until making a clinical decision about a physiopathology or infection through medicals analysis. Nucleic acid amplification methods continue to play a role in these medicals analysis processes, but, many gold conventional standard Methods are timeconsumers, less sensitive, technically challenging. It is that reason why recently, after the development of the PCR technique; the real-time PCR became a frequently requested tool to diagnose the virus, bacteria, fungal and parasites infections in different pathologies, especially in developed countries. However, its availability remains a big problem in resource-limited countries like Africa continent. It is because of the issue due to cost, technology, human resource constraints and the remote areas with limited access to laboratory facilities which stays also a major problem.

Nucleic acids amplification methods remain to be expensive, not accessible for all laboratories. In addition to this, they are easily inhibited and contaminated by the other biochemical reagents time-
\end{abstract}

*Corresponding author: E-mail: ab.soukri@gmail.com, tuwiringiyeyezu@yahoo.fr; 
consumer, for this reason, other methods of nucleic acid amplification under isothermal conditions have emerged each with its particularities. Despite their successes, molecular biology should have a method that combines many of the advantages and accessible everywhere. So, in 2000, the LAMP method was developed and offered many advantages such as speed, specificity, high sensitivity and the cost of very low equipment. In this review, we present the different studies to confirm the advantages of LAMP that we consider as an alternative to PCR in molecular diagnostics with a wide range of use on clinical samples and in scientific research and also, the method to save the Africans patients from the high cost and time consuming of other amplification methods.

Keywords: Polymerase chain reaction; loop-mediated isothermal amplification; molecular diagnosis; biological samples; diagnostic methods; medicals analysis.

\section{INTRODUCTION}

Loop-mediated isothermal amplification LAMP is a nucleic acids amplification method which principle is the reaction carried out with a set of 4 to 6 primers to recognize 6 to 8 distinct target sequences of DNA regions, it is based on Loop and uses the strand displacement activity of Bst Polymerase (Bacillus stearothermophilus) conditioned about 60 to $65^{\circ} \mathrm{C}$.

It is a novel isothermal amplification method and is used in rapid diagnostic testing of viruses [1], bacteria [2], fungi [3], and parasites [4] in all sorts of biological samples. Derived from the famous classical polymerase chain reaction (PCR), it presents many advantages like to be low-cost, no thermocycler required, tolerant to sample matrix inhibitors And it performs with the various products detection methods like fluorescent dye, real-time detection, lateral flow assays, and gel analysis [Fig. 1] but it is difficult to multiplex as a disadvantage compared with classical PCR or other amplification methods; this method amplifies the nucleic acids with high specificity, efficiency, and rapidity under isothermal conditions [5]. It was more sensitive than the gold standard method and performed in the early stages of infectious manifestations and used in cases for which differentiating infectious agents is difficult [6].

It helped to differentiate the infection from the different agents of the same family and in the clinical decision about the therapeutic agent to use for treatments that differ from infectious agent to other [7]. In addition to this, it is a good choice in molecular diagnostics because of its high degree of specificity without cross-reactivity, efficiency, and speed [5] than almost of conventional methods for the diagnosis of different pathologies. LAMP shows to be simple and it doesn't require a well-equipped laboratory. It has also the privilege to examine the results with the naked eye to detect the positive reaction with a high concordance rate with the conventional PCR results [1].

Advantages of LAMP have pushed the different researchers to evaluate this method and concluded the interesting results like the effectiveness, valuable, robustness and power of this innovative method [6] The use of more than four primers is a special feature which offers this method a high specificity which was evaluated in several viral and bacterial species which are commonly present in same specimens [8] or same family [1] this method has shown the positivity without cross-reactivity or false positivity. It was also tested and succeeded in renal transplant recipients [9] and concluded his potentiality to be developed for "point of care". It is a simple tool to reduce the cost of medicine to the immunocompromised patients infected with the opportunists' virus [10] it is known to tolerate the biological substances contamination and low inhibition rate. The comparison of LAMP and PCR has given the possibility to understand the detection limit and clarification about sensitivity and specificity in different assays. It was useful to understand the association between congenital human infection and active maternal infection during pregnancy [11].

\section{THE PERFORMANCE OF LOOP- MEDIATED ISOTHERMAL AMPLIFICA- TION WITH OTHER DIAGNOSTICS METHODS}

Patient treatments require sure diagnostics process. The clinical decision is suggested by the medicals analysis results. Today, many methods are proposed in different medicals 


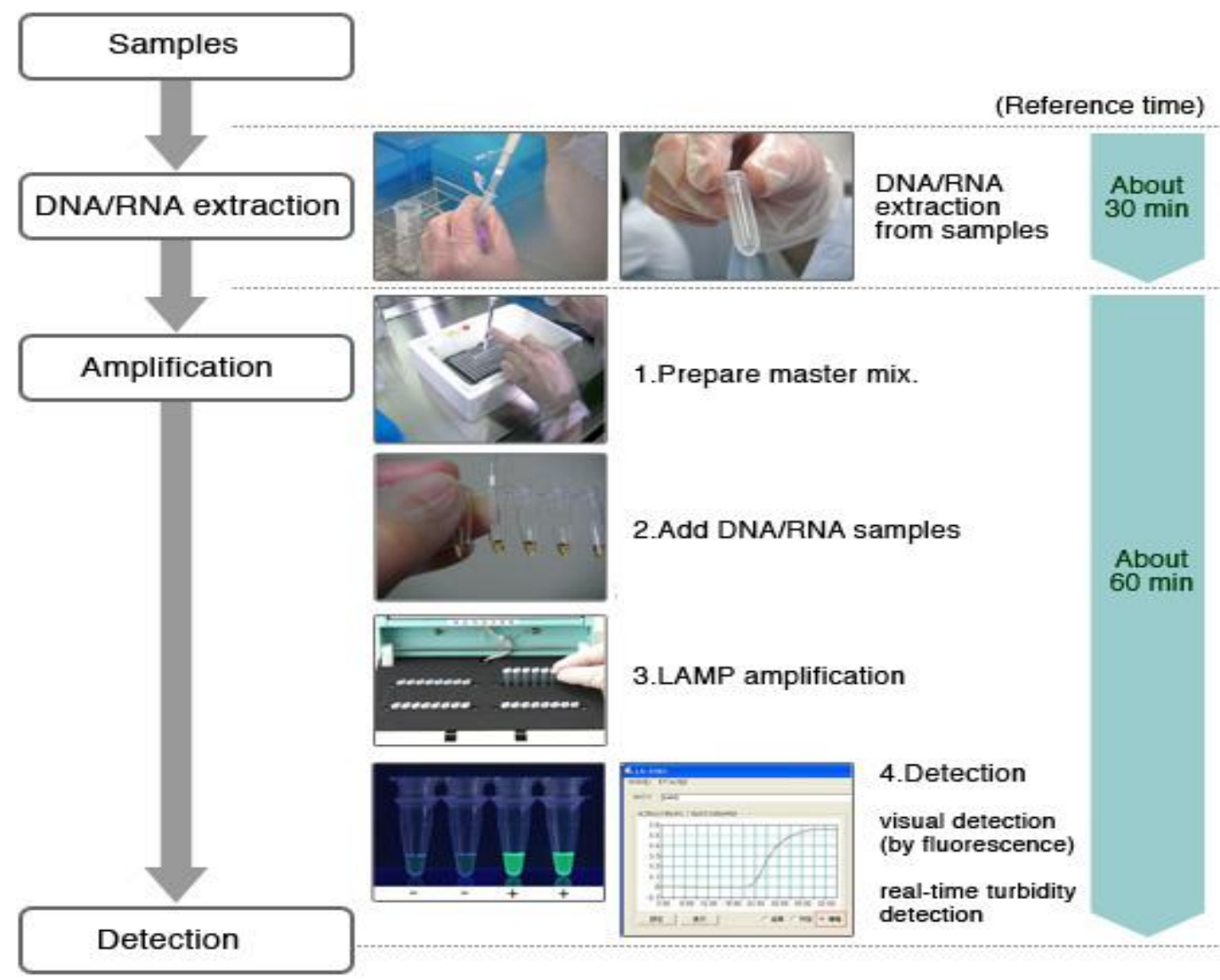

Fig. 1. Standard procedure using LAMP method, it is simple, rapid, specific and cost-effective the master mix consists of primers, DNA polymerase with strand displacement activity, dNTPs, reaction buffer added DNA/RNA samples and Reverse transcriptase (in case of RNA), and The procedure simply consists of incubating the template sample and the above reagents at a constant temperature between $60-65^{\circ} \mathrm{C}$ for 15 minutes to 1 hour, the amplification can be detected through the presence of amplified product. [Figure from Eiken chemical genome site]

[5]

domains to perform. But some methods make more advantageous than others because of short timing, efficiency, sensitivity and the cost of methods to save the patient's life. It's known that to have more different diagnostics methods for the same medicals analysis demands stay obligatory in laboratory statements guide, this, is to make sure of results quality control. To choose these methods may request the advantages of the feasibility of one to the other method comparing the results concordance rate. There are several diagnostics methods for the detection of infection in clinical and environmental samples [Table 1]. The problem stays that the gold standard methods for diagnosis are not sensitive, expensive, technically challenging and time consuming due to the false positivity and the use of thermocycler. The early false seronegativity because of antibody screening lack for example before conception of pregnancy woman stays a problematic to the newborn. In addition to this, the cross-reactivity error complicates those methods. some infection requires the invasive test like a histopathological examination that is limited in application [12]. LAMP is accessible for all, its methods process can be conducted in the laboratory water bath or heating block and amplifies the nucleic acids in isothermal conditions about $63^{\circ}$ to $65^{\circ} \mathrm{C}$ [4].

LAMP performs in microorganisms' detection. Here, the conventional culture methods are requested, but, this culture takes more than a day for isolating and identification of pathological microorganism that stays time-consuming, Using LAMP in the same condition, the results will be ready about less than 90 minutes [13]. This method is a time-saver; it can also play the role of quality control of some culture major 
Table 1. Table for comparing performance of LAMP method with other diagnostics methods

\begin{tabular}{|c|c|c|c|c|c|}
\hline Authors & Target pathogen agent & Comparison methods & Limit of detection & Sensitivity & Specificity \\
\hline Kelly A et al. [20] & Treponeme strains & RT-PCR & $\leq 70 \mathrm{fg} / \mu \mathrm{l}$ & $100 \%$ & $100 \%$ \\
\hline Yamazaki W et al. [13] & Campylobacter spp. & Direct plating & $5.6 \times 103 \mathrm{CFU} / \mathrm{g}$ & $81.3 \%$ & $96.6 \%$ \\
\hline Xiaoli Wang et al. [11] & Cytomegalovirus & RT-PCR & $>10$ copies/tube & $86.96-100 \%$ & $97.24-100 \%$ \\
\hline Chang-ki Kim et al. [15] & Pulmonary tuberculosis & SM & unspecified & $92.0 \%$ & $58.8 \%$ \\
\hline Guang xiang W et al. [16] & Orf virus & QRT-PCR & 10 copies/ tube & $89.13 \%$ & $100 \%$ \\
\hline Xing-Wei $\mathrm{N}$ et al. [21] & Echinococcus granulosus & Copro-ELISA & unspecified & $100 \%$ & $88.8 \%$ \\
\hline Sotiriadou I et al. [19] & Toxoplasma gondii & IFT & unspecified & $100 \%$ & $100 \%$ \\
\hline Bakhtiaria $S$ et al. [8] & Helicobacter pylori & PCR & 102 CFU/ tube & $100 \%$ & $100 \%$ \\
\hline Adama L. Bet al. [22] & Pulmonary tuberculosis & Genexpert & unspecified & $99.0 \%$ & $94.0 \%$ \\
\hline Yoshiki M et al. [23] & Staphylococcus aureus & Drt-PCR & unspecified & $92.3 \%$ & $100 \%$ \\
\hline Sema M et al. [24] & Plasmodium falciparum & Film microscopy & unspecified & $96.8 \%$ & $84.3 \%$ \\
\hline
\end{tabular}

SM: smear microscopy, RT-PCR: Real-time polymerase chain reaction, QRT-PCR: Quantitative PCR, Copro-ELISA: coproculture coupled with enzyme-linked immunosorbent assay, IFT: immunofluorescence test, Drt-PCR: Duplex real-time polymerase chain reaction 
contaminants like Mycoplasma [14]. It is known that the routine viral culturing may be sufficiently sensitive for the identification of some virus like cytomegalovirus. However, this method is labor-intensive and subjective and also it may take more than 14 days for the virus to be propagated and identified [11]. That shows the advantages to use this isothermal method. In addition to this, the routine sputum smear microscopy has been the primary method for the diagnosis of pulmonary tuberculosis. But, when the bacterial load is less than 10.000 organisms per milliliter, the sensitivity is grossly compromised. It means smear microscopy has a significant limitation in its performance so in this case TB-LAMP has performed and it could be used as a quality controller of smear microscopy results because of its high sensitivity and simplicity as it can be read with the naked eye under ultraviolet light [15]. It could help save the patients in low and middle income-countries where the mortality increases.

The sensitivity of the LAMP shows being the same with whose classical PCR [16]. Some time more sensitive and reliable than conventional PCR [17], it may be because of the omission of DNA purification step and the take away of the thermocycler. Without forgetting the tolerance of LAMP to the different biological substances [18] while Multiplex PCR shows some crossreactivity, contamination, and inhibition in some microorganism's species. In this way immunofluorescence has shown being less sensitive, and, it makes many false-negative results in some samples whereas LAMP stays efficient [19]. Generally, all diagnostics and research methods show the role in specifics areas. So, to Integrate LAMP could play a role and offer the advantages of low costing and time-consuming through its potentiality to detect early the specific infection or contamination and it will help for confirmation of results, quality control and the efficiency of medicals process.

\section{LAMP WITH THE BIOLOGICAL SAMPLES IN CLINICAL ASSAYS}

To validate the usefulness of this method in the different biological samples, many pieces of research were reported and LAMP method has been performed to all kinds of liquid biological samples like whole blood, urine, feces, vaginal samples, cerebrospinal fluid, bone marrow, ascites fluid, pleural fluid and ocular liquid vitreous specimens [1]. The various pathogen agents were detected to prove the application of LAMP method from asymptomatic to symptomatic. Infection and children to adults.

\subsection{Bacterial Detection}

The bacterias are found in many different infectious diseases as causal agent. LAMP method has been used to detect staphylococcus aureus a most important pathogen of nocosomial infection [23] and it appeared to be a sensitive and reliable novel method to diagnose MRSA bloodstream infection for appropriate antibiotic therapy. Even if, the growth rate of Mycobacterium tuberculosis stays slow, this method has also proven his efficiency through its high sensitivity for early detection [27] and it stays a fast noninvasive method to detect the helicobacter pylori where it can be used alternatively with other serological methods [28].

\subsection{Fungal Detection}

Fungi stay the dangerous infection to the immunocompromised patients in the world, LAMP method may be very important tool where fungal infections are the major cause of morbidity and mortality in debilitated or immunocompromised patients like Candida albicans [30]. This nucleic acid amplification method stays the only molecular method to be on-site testing application because of his advantages of simplicity and rapidity without the well-equipped laboratory; it can be used for phytopathogenic, mycotoxigenic, and medically relevant fungi and yeasts [31]. LAMP was performed in different aspects of fungial infection and it was able to detect with specificity the pathogenic species [32]. The spread of dermatophytosis caused by Trichophyton tonsurans among contact sports athletes was identified with LAMP method [33]. The respiratory infection like Histoplasma capsulatum in the endemic region with a high mortality rate [34] and the conditional pathogen which is the major cause of life-threatening in immunocompromised patients like Aspergillus fumigates [35]. This shows that LAMP method is very used because of the advantages that it has.

\subsection{Viral Detection}

The method LAMP has always his place as the low cost and rapid diagnosis method; it is a 
method who resolves many public health problems in diagnostic about the price of chronic diseases like Hepatitis C [25]. It has expanded its detection range until some virus which has a highly contagious nature where the disease could be rapidly spread in close communities like influenza [29]. Without forgetting Zika infection during pregnancy which can lead to miscarriage and severe neurological birth defects [26]. This test is recommended like an easily distributed and implemented method to fight against the highly virulent virus in humans as Ebola hemorrhagic fever in West Africa.

\subsection{Parasites Detection}

The parasites are not isolated in LAMP method detection, because, it has been performed to detect Plasmodium sp. which is an intraerythrocytic parasite the pathogen agent of Malaria $[37,57,58]$. Leishmania an Intraleucocytic parasite [64] and Extracellular parasite like trypanosome brucei [65]. So, with LAMP amplification these parasites can be detected on low cost and rapidly and save the patients economic crisis.

\section{COMBINATION AND MODIFICATION OF LAMP AS A NOVEL POWER OF SUCCESS}

In the beginning, this method was just for DNA amplification, after the success of classical LAMP method, some modifications were developed and evaluated to empower this method for being optimized and unlimited. RT-LAMP was developed and evaluated by taking it a step further and combining it with a reverse transcription phase to allow the detection of RNA. it is similar to RT-PCR and uses reverse transcriptase to synthesize complementary DNA (cDNA) from RNA sequences. This cDNA is then amplified with LAMP protocol method in isothermal conditions between 60 and $65^{\circ} \mathrm{C}$. RTLAMP was developed to detect the retrovirus range in infectious diseases like Dengue virus [36], foot-and-mouth-disease virus and its serotypes [37], Potatovirus Y [38].

To facilitate the clinicals detection in endemic countries, the portable device capable of performing both the amplification and detection (by fluorescence) of LAMP in one platform was developed and this real-time fluorescence LAMP was useful in Malaria detection [39].

Digital microfluidic flow is a device that arises the next step in the fast-evolving field of operating platforms in molecular diagnostics, to detect the LAMP products DMF-LAMP was developed [40]. This microfluidic device is made up of the valves, mixers, and pumps capable of controlling the fluid flow within the device and other components useful for sample pre-treatments or detection, this microfluidic-coupled LAMP amplification was developed and the application was automated nucleic acid amplification of classical LAMP protocol.

Even if LAMP method is known to detect a single target, it can also be developed to achieve multiplex LAMP-based detection like a novel approach called the multiple endonuclease restriction real-time LAMP assay [41] this is an extension of LAMP to accommodate targetspecific, robust and multiplex detection, provides a molecular diagnostic tool with less detection time, high sensitivity and specificity compared with those of LAMP and quantitative real-time PCR. The parasitic DNA can serve as molecular biomarkers and this method LAMP can perform to detect their presence in the human host like Helminthes Infections [42] and Malaria [43]. Also, in the most important neglected diseases like visceral leishmaniasis [44].

The simplicity of the LAMP method can also perform on paper-based diagnostics devices with the advantages of detecting multiple DNA targets [45]. This device has received particular attention because paper is a simple, low-cost material. The paper has natural microfluidic channels and has a natural capillary action through their porous structures and it has been accepted as a great alternative for future POC testing. This device was performed in bacterial meningitis dans détection.

Not only the DNA target, LAMP can be modified and use detecting the pathogen-specific antibodies like LAMPole [42] that consists a conjugation chemistry that bonds the DNA element to the polypeptide without inhibiting IgGbinding activity or interfering with the ability to promote LAMP, here, it is possible to measure protein analytes by creating a protein-DNA fusion. LAMP has been modified to permit having a large using interval range of detection like The Direct Boil-LAMP method In the parasitic pathogen detection of cutaneous leishmaniasis [46].

LAMP method can be combined with malachite green to make a rapid colorimetric assay, here, the different concentrations of malachite green 
can be added with LAMP reaction mixture and the products will be detected by naked eyes.it was performed to detect an haemoplasmas feline, the infectious agent of feline anaemia [47].

LAMP method can be combined with lateral flow dipstick-based and uses a biotin product hybridized with a digoxin-labeled DNA probe that is complexed with a gold-labeled anti-digoxin antibody; this assay has been an alternative method of immunoblot assay. It was helpful to develop a novel strategy that enabled to detect the nucleotide mutations using single-step and close-tube reactions primer-activatable LAMP (PA-LAMP) [48] this has shown that Loopmediated isothermal amplification LAMP is a useful platform for nucleic acids detection in point-of-care (POC). The genetic diversity based on mitochondrial DNA (mtDNA) D-loop sequence [49] was performed using this method to know the species-specificity [50].

To optimize the maximum quality results of this nucleic amplification method, it was shown that pullulan can reduce the non-specific amplification which will be the advantageous benefits comparing to the using of bovine serum albumin, DL-dithiothreitol, dimethyl sulfoxide, tetramethylene sulfoxide and glycerol [51].

Using the LAMP methods gives many manners for detecting the results like gel analysis, realtime turbidimeter detecting, fluorescence dye, lateral flow dipstick LAMP-LFD that consists using of biotin labeling primers in LAMP mixture and digoxin hybridization probe and it has shown to be most sensitive 1000 times than conventional PCR [52]. LAMP can help to know the Food poisoning frequently caused by the accidental ingestion of toxic plants with strong morphological similarities through its absolute specificity to edible plants for example false helleborine (Veratrum album), which is a commonly involved in such incidents [53] By chemical analysis of natural compounds.

The LAMP products can be detected as portable to provide a rapid and effective determination for disease pathogens. For this, it has developed a handheld, automatic and detection system-free thermal digital microfluidic (DMF) device for DNA detection [54]. Through the different researches around, it reported the success of this isothermal method on DNA and RNA that has pushed the scientists far again in research like RT-LAMP to detect the Zika Virus in Brasil [55].
LAMP can use the properties of Rolling circle replication to detect the micro RNA [56]. The results of LAMP modification upgraded the quality and open access to other biomedical methods and make LAMP the technique of the future. It is reported that LAMP sensitivity can be increased by adding a denaturation step about $96^{\circ} \mathrm{C}$ for 5 minutes before incubation of reaction mixture at isothermal conditions [10], This modification has helped to expand the detection range of LAMP about the clinical samples with early infections [57].

\section{THE NON-DEVELOPED COUNTRIES PROFIT TO SAVE THE COST OF MEDICAL ANALYSIS}

World Health Organization reports that subSaharan Africa confronts the world's most dramatic public health crisis this is added to the fact that more people in Africa have little-income. Medicals analyses are involved in the monitoring of our daily lives in clinical decision making, but the cost constraints stay a challenge, LAMP method is performing as proof that scientific researches can defy medicals analysis cost visual view to the advantages that this method presents.

This method can be helpful like a portable device and low-cost to help in on-site diagnostics in nondeveloped countries especially in remotes regions where there are any medicals infrastructures like a laboratory and the endemics diseases like malaria and Ebola can be constantly inspected. LAMP amplification method doesn't require a DNA extraction step and the thermocycler, this is very beneficial in shortening the diagnosis time and cut the cost of the use of real-time PCR which is costly and found only in the well-equipped laboratory [58]. The study has reported the detection of tuberculosis, sleeping sickness, and recently Strongyloides with the LAMP method; this decreases the economic loss in patient's people profits $[59,60]$.

Based on the advantageous roles that can play LAMP in the different molecular diagnostic system and this manner to relate this method with technology make it the future ambitious method to evaluate again.

The application of this Loop-mediated isothermal amplification in evaluating and managing diagnosis in certain types of disease, such as acute malaria $[61,62]$ and it has given a new 
dimension to the gradually growing field of minimal residual disease management. The simplicity, sensibility, and specificity of loopmediated isothermal amplification put it in a very good position for future development in lifethreatening disease diagnosis. It is anticipated that the loop-mediated isothermal amplification market will grow significantly during the forecast period, owing mainly due to the demand for advanced molecular diagnostics to accurately diagnose life-threatening diseases. Global demand for loop-mediated isothermal amplification technology grows day by a day with various product types. It will continue to find the highest applicability in both research and diagnostics [63].

Loop-mediated isothermal amplification using DNA polymerase has seen a rapid advance in the past several years due to the high adoption of loop-mediated isothermal amplification in diagnostics and clinical tests.

In regions of sub-Saharan Africa where malaria removal is targeted, new tools and approaches are needed to achieve this ambitious goal, The sensitive diagnostic test for different infections blood-film microscopic analysis of Malaria PCR is a gold standard for the sensitive diagnosis of molecular diagnostics methods but it has some limitations that make it unavailable in poor subSaharan Africa countries, this last gives LAMP advantages because it is a simple, inexpensive molecular test for Plasmodium falciparum that is correlated to the parasite counts obtained by blood-film microscopic analyses with same sensitivity, so LAMP is an effective tool for malaria diagnosis at a field clinic in a field setting [64] it is more sensitive than PCR assays [65], sometimes PCR identified infections that LAMP did not detect and vice versa but LAMP testing stays easy to scale-up in field conditions requiring minimal training and equipment, with results ready one to three hours after screening [66]. Molecular methods are more important in clinical diagnostics, the different researches studies that were brought in various types' infections and have approved LAMP as an alternative technique of conventional PCR and the sensitivity is relatively at the care taken when designing the primers that are more specific to the target gene.

\section{CONCLUSION}

LAMP is a nucleic acid amplification method accessible to operate using the simple laboratory material and isothermal condition that omits the use of expensive thermocyclers, it is a more sensitive diagnostic tool that may be useful in the non-developed countries to save the cost of realtime PCR, it will help in diseases control and reducing of economics loss for patient' people profits. It is used in laboratory-like a valuable alternative method of other conventional standard methods with many advantages and it is present in direct and serological diagnostics.

The different researches report that it can be used to all kinds of samples like whole blood, urine, and other biological liquids and it is considered to perform with specificity, rapidity, high sensitivity and low costing. More advantageous than other PCR derived methods, it is used in rapid diagnosis of viral, bacterial and parasitic diseases; it is applying to such fields as medicine, agriculture, food, animal husbandry, and environment. The modification was tested to empower this method for being unlimited and permitting to have a large using interval range.

The progress of researches about molecular diagnostics methods in medicals analysis is needed, the reason is to continue the enhancement of LAMP utility and its applications for the infectious disease diagnosis in low and middle-income countries like Africa, it will save patients 'life and eradicate the economic crisis.

\section{COMPETING INTERESTS}

Authors have declared that no competing interests exist.

\section{REFERENCES}

1. Reddy AK, Balne PK, Reddy RK, Mathai A, Kaur I. Development and evaluation of loop-mediated isothermal amplification assay for rapid and inexpensive detection of cytomegalovirus DNA in vitreous specimens from suspected cases of viral retinitis. Journal of Clinical Microbiology. 2010;48(6):2050-2052.

2. Birmpa A, Kalogeropoulos K, Kokkinos $P$, Vantarakis A. Evaluation of two loopmediated isothermal amplification methods for the detection of Salmonella enterica and Listeria monocytogenes in artificially contaminated ready-to-eat fresh produce. Italian Journal of Food Safety. 2015;4(3).

3. Tatibana BT, Sano A, Uno J, Kamei K, Igarashi $\mathrm{T}$, Itano $\mathrm{EN}$, et al. Detection of 
Paracoccidioides brasiliensis gp43 Gene in Sputa by Loop-Mediated Isothermal Amplification Method. Journal of Clinical Laboratory Analysis. 2009;23(2):139-143.

4. Njiru ZK, Mikosza ASJ, Matovu E, Enyaru JCK, Ouma JO, Ndung'u JM, et al. African trypanosomiasis: Sensitive and rapid detection of the sub-genus Trypanozoon by loop-mediated isothermal amplification (LAMP) of parasite DNA. International Journal for Parasitology. 2008;38(5):589599.

5. Notomi T, Okayama $\mathrm{H}$, Masubuchi $\mathrm{H}$, Yonekawa T, Watanabe K, Amino N, et al. Loop-mediated isothermal amplification of DNA. Nucleic Acids Research. 2000;28 (12):e63-e63.

6. Knox CM, Chandler D, Short GA, Margolis, TP. Polymerase chain reaction-based assays of vitreous samples for the diagnosis of viral retinitis: Use in diagnostic dilemmas. Ophthalmology. 1998;105(1): 37-45.

7. Madhavan HN, Priya K, Biswas J. Current perspectives of herpesviral retinitis and choroiditis. Indian Journal of Pathology \& Microbiology. 2004;47(4):453-468.

8. Bakhtiari $\mathrm{S}$, Alvandi A, Pajavand $\mathrm{H}$, Navabi J, Najafi F, Abiri R. Development and diagnostic evaluation of loop-mediated isothermal amplification using a new gene target for rapid detection of Helicobacter pylori. Jundishapur Journal of Microbiology. 2016;9(5).

9. Bista BR, Ishwad C, Wadowsky RM, Manna P, Randhawa PS, Gupta G. Development of a loop-mediated isothermal amplification assay for rapid detection of $\mathrm{BK}$ virus. Journal of Clinical Microbiology. 2007;45(5):15811587.

10. Suzuki R, Yoshikawa T, Ihira M, Enomoto Y, Inagaki S, Matsumoto K. Development of the loop-mediated isothermal amplification method for rapid detection of cytomegalovirus DNA. Journal of Virological Methods. 2006;132(1-2):216221.

11. Wang X, Li X, Hu S, Qu H, Zhang Y, Wang $X$, et al. Rapid detection of active human cytomegalovirus infection in pregnancy using loop-mediated isothermal amplification. Molecular Medicine Reports. 2015;12(2):2269-2274.

12. de Vries JJ, van der Eijk AA, Wolthers KC, Rusman LG, Pas SD, Vossen AC, et al. Real-time PCR versus viral culture on urine as a gold standard in the diagnosis of congenital cytomegalovirus infection. Journal of Clinical Virology. 2012;53(2): 167-170.

13. Yamazaki W, Taguchi M, Kawai T, Kawatsu K, Sakata J, Inoue K, et al. Comparison of loop-mediated isothermal amplification assay and conventional culture methods for detection of Campylobacter jejuni and Campylobacter coli in naturally contaminated chicken meat samples. Appl. Environ. Microbiol. 2009; 75(6):1597-1603.

14. Soheily Z, Soleimani M, MajidzadehArdebili K. Detection of Mycoplasma contamination of cell culture by A loopmediated isothermal amplification method. Cell Journal (Yakhteh). 2019;12(1).

15. Kim CK, Cho EA, Shin DM, Choi SW, Shin SY. Comparative evaluation of the loopmediated isothermal amplification assay for detecting pulmonary tuberculosis. Annals of Laboratory Medicine. 2018; 38(2):119-124.

16. Wang $G$, Shang $Y$, Wang $Y$, Tian $H$, Liu X. Comparison of a loop-mediated isothermal amplification for orf virus with quantitative real-time PCR. Virology Journal. 2013; 10(1):138.

17. Wang $\mathrm{X}$, Seo DJ, Lee $\mathrm{MH}$, Choi C. Comparison of conventional PCR, multiplex PCR, and loop-mediated isothermal amplification assays for rapid detection of Arcobacter species. Journal of Clinical Microbiology. 2014;52(2):557-563.

18. Ni XW, MC Manus DP, Lou ZZ, Yang JF, Yan HB, Fan YL, et al. A comparison of Loop-Mediated Isothermal Amplification (LAMP) with other surveillance tools for Echinococcus granulosus diagnosis in canine definitive hosts. PLoS One. 2014; 9(7):e100877.

19. Sotiriadou I, Karanis P. Evaluation of loopmediated isothermal amplification for detection of Toxoplasma gondii in water samples and comparative findings by polymerase chain reaction and immunofluorescence test (IFT). Diagnostic Microbiology and Infectious Disease. 2008; 62(4):357-365.

20. Anklam K, Kulow M, Yamazaki W, Döpfer D. Development of real-time PCR and Loop-Mediated Isothermal Amplification (LAMP) assays for the differential detection of digital dermatitis associated treponemes. PloS One. 2017;12(5): e0178349. 
21. Ni XW, McManus DP, Lou ZZ, Yang JF, Yan HB, Li L, Fan YL .A comparison of Loop-Mediated Isothermal Amplification (LAMP) with other surveillance tools for Echinococcus granulosus diagnosis in canine definitive hosts. PLoS One. 2014; 9(7):e100877.

22. Bojang AL, Mendy FS, Tientcheu LD, Otu J, Antonio M, Kampmann B, Sutherland JS. Comparison of TB-LAMP, GeneXpert MTB/RIF and culture for diagnosis of pulmonary tuberculosis in The Gambia. Journal of Infection. 2016;72(3):332-337.

23. Misawa $Y$, Yoshida A, Saito R, Yoshida $H$, Okuzumi K, Ito N, Koike K. Application of loop-mediated isothermal amplification technique to rapid and direct detection of methicillin-resistant Staphylococcus aureus (MRSA) in blood cultures. Journal of Infection and Chemotherapy. 2007;13(3): 134-140.

24. Sema M, Alemu A, Bayih AG, Getie S, Getnet G, Guelig D, Pillai DR. Evaluation of non-instrumented nucleic acid amplification by loop-mediated isothermal amplification (NINA-LAMP) for the diagnosis of malaria in Northwest Ethiopia. Malaria Journal. 2015;14(1):44.

25. Kargar M, Askari A, Doosti A, GhorbaniDalini S. Loop-mediated isothermal amplification assay for rapid detection of hepatitis $\mathrm{C}$ virus. Indian Journal of Virology. 2012;23(1):18-23.

26. Bartolone SN, Tree MO, Conway MJ, Chancellor MB, Lamb LE. Reverse Transcription-Loop-Mediated Isothermal Amplification (RT-LAMP) assay for Zika virus and housekeeping genes in urine, serum and mosquito samples. JoVE (Journal of Visualized Experiments). 2018; (139):e58436.

27. Iwamoto $T$, Sonobe T, Hayashi K. Loopmediated isothermal amplification for direct detection of Mycobacterium tuberculosis complex, Mycobacterium avium and $M$. intracellulare in sputum samples. Journal of Clinical Microbiology. 2003;41(6):26162622.

28. Yari F, Abiri R, Aryan E, Ahmadi Jouybari T, Navabi J, Alvandi A. Loop-mediated isothermal amplification as a fast noninvasive method of helicobacter pylori diagnosis. Journal of Clinical Laboratory Analysis. 2016;30(5):464-470.

29. Poon LL, Leung CS, Chan $\mathrm{KH}$, Lee JH, Yuen KY, Guan Y, et al. Detection of human influenza $A$ viruses by loop- mediated isothermal amplification. Journal of Clinical Microbiology. 2005;43(1):427430.

30. Noguchi $H$, Iwase $T$, Omagari D, Asano M, Nakamura R, Ueki K, et al. Rapid detection of Candida albicans in oral exfoliative cytology samples by loop-mediated isothermal amplification. Journal of Oral Science. 2017;59(4):541-547.

31. Niessen L, Vogel RF. Detection of Fusarium graminearum DNA using a LoopMediated Isothermal Amplification (LAMP) assay. International Journal of Food Microbiology. 2010;140(2-3):183-191.

32. Amirabadi AR, Shahhosseiny $\mathrm{MH}$, Yousefi JV, Ghahri M. Loop Mediated Isothermal Amplification (LAMP) in diagnosis of neorocryptococcosis. African Journal of Biotechnology. 2012;11(17): 3986-3992.

33. Yo A, Yamamoto $M$, Nakayama $T$, Ishikawa J, Makimura K. Detection and identification of Trichophyton tonsurans from clinical isolates and hairbrush samples by loop-mediated isothermal amplification system. The Journal of Dermatology. 2016;43(9):1037-1043.

34. Scheel CM, Zhou Y, Theodoro RC, Abrams B, Balajee SA, Litvintseva AP. Development of a loop-mediated isothermal amplification method for detection of Histoplasma capsulatum DNA in clinical samples. Journal of clinical Microbiology. 2014;52(2):483-488.

35. Tang $Q$, Tian S, Yu N, Zhang X, Jia X, Han $L$, et al. Development and evaluation of a loop-mediated isothermal amplification method for rapid detection of Aspergillus fumigatus. Journal of Clinical Microbiology. 2016;54(4):950-955.

36. Carrillo C, Werbajh S, Malnero C, Stolowicz F, Larocca L, Malirat V, et al. Development of a colorimetric RT-LAMP amplification assay adapted to an early and easy detection of Dengue virus. International Journal of Infectious Diseases. 2018;73:171.

37. Maryam S, Rasheed T, Latif A, Zahra R, Zahur AB, Farooq U, et al. One-step realtime loop-mediated isothermal amplification (RT-LAMP): Evaluation and its application for the detection of foot-andmouth-disease virus and its serotypes. Turkish Journal of Veterinary and Animal Sciences. 2017;41(3):435-443.

38. Nie X. Reverse transcription loop-mediated isothermal amplification of DNA for 
detection of Potato virus Y. Plant Disease. 2005;89(6):605-610.

39. Su Y, Yang Y, Peng Q, Zhou D, Chen Y, Wang Z, et al. Development and application of a rapid and visual loopmediated isothermal amplification for the detection of Sporisorium scitamineum in sugarcane. Scientific Reports. 2016;6: 23994.

40. Coelho B, Veigas B, Águas H, Fortunato E, Martins R, Baptista $P$, et al. A digital microfluidics platform for loop-mediated isothermal amplification detection. Sensors. 2016,17(11).

41. Wang $\mathrm{Y}$, Wang $\mathrm{Y}$, Lan $\mathrm{R}, \mathrm{Xu} \mathrm{H}, \mathrm{Ma} \mathrm{A}$, Li $D$, et al. Multiple endonuclease restriction real-time loop-mediated isothermal amplification: A novel analytically rapid, sensitive, multiplex loop-mediated isothermal amplification detection technique. The Journal of Molecular Diagnostics. 2015;17(4):392-401.

42. Biswal D. Advances in Loop-Mediated Isothermal Amplification (LAMP) technology and its necessity to detect helminth infections: An overview. Biomarkers J. 2016;2(2):1-5.

43. De Koninck AS, Cnops L, Hofmans M, Jacobs J, Van den Bossche D, Philippé J. Diagnostic performance of the loopmediated isothermal amplification (LAMP) based illumigene ${ }^{\circledR}$ malaria assay in a nonendemic region. Malaria Journal. 2017; 16(1):418.

44. Abbasi I, Kirstein OD, Hailu A, Warburg A. Optimization of Loop-Mediated Isothermal Amplification (LAMP) assays for the detection of Leishmania DNA in human blood samples. Acta Tropica. 2016;162: 20-26.

45. Seok $Y$, Joung HA, Byun JY, Jeon HS, Shin SJ, Kim S, et al. A paper-based device for performing loop-mediated isothermal amplification with real-time simultaneous detection of multiple DNA targets. Theranostics. 2017;7(8):2220.

46. Mikita K, Maeda T, Yoshikawa S, Ono T, Miyahira Y, Kawana A. The direct boilLamp method: A simple and rapid diagnostic method for cutaneous leishmaniasis. Parasitology International. 2014;63(6):785-789.

47. Nzelu CO, Cáceres AG, Guerrero-Quincho $\mathrm{S}$, Tineo-Villafuerte E, Rodriquez-Delfin L, Hashiguchi $Y$, et al. A rapid molecular diagnosis of cutaneous leishmaniasis by colorimetric malachite green-Loop-
Mediated Isothermal Amplification (LAMP) combined with an FTA card as a direct sampling tool. Acta Tropica. 2016;153: 116-119.

48. Du WF, Ge JH, Li JJ, Tang LJ, Yu RQ, Jiang JH. Single-step, high-specificity detection of single nucleotide mutation by primer-activatable loop-mediated isothermal amplification (PA-LAMP). Analytica chimica acta. 2019;1050:132138.

49. Zhang $\mathrm{T}$, Lu $\mathrm{H}$, Chen $\mathrm{C}$, Jiang $\mathrm{H}, \mathrm{Wu} \mathrm{S}$. Genetic diversity of mtDNA D-loop and maternal origin of three Chinese native horse breeds. Asian-Australasian Journal of Animal Sciences. 2012;25(7):921.

50. Kumari S, Kumar RR, Mendiratta SK, Kumar D, Rana PD, Jawla J, et al. Species-specific Loop-Mediated Isothermal Amplification (LAMP) assay for identification of tissue of cattle origin by targeting mitochondrial gene sequences. 3 Biotech. 2019;9(3):69.

51. Gao X, Sun B, Guan Y. Pullulan reduces the non-specific amplification of LoopMediated Isothermal Amplification (LAMP). Analytical and Bioanalytical Chemistry. 2019;411(6):1211-1218.

52. Zhang J, Cao J, Zhu M, Xu M, Shi F. Loopmediated isothermal amplification-lateralflow dipstick (LAMP-LFD) to detect Mycoplasma ovipneumoniae. World Journal of Microbiology and Biotechnology. 2019;35(2):31.

53. Kikkawa HS, Aragane M, Tsuge K. Species identification of white false hellebore (Veratrum album subsp. oxysepalum) by Loop-Mediated Isothermal Amplification (LAMP). Forensic Toxicology. 2019;37(2):308-315.

54. Wan L, Gao J, Chen T, Dong C, Li H, Martins RP, et al. Lamp Port: A handheld digital microfluidic device for loop-mediated isothermal amplification (LAMP). Biomedical microdevices. 2019;21(1):9.

55. Kurosaki $Y$, Magassouba NF, Oloniniyi OK, Cherif MS, Sakabe S, Yasuda J, et al. Development and evaluation of reverse transcription-loop-mediated isothermal amplification (RT-LAMP) assay coupled with a portable device for rapid diagnosis of Ebola virus disease in Guinea. PLoS Neglected Tropical Diseases. 2016;10(2): e0004472.

56. Tian W, Li P, He W, Liu C, Li Z. Rolling circle extension-actuated Loop-Mediated Isothermal Amplification (RCA-LAMP) for 
ultrasensitive detection of micro RNAs. Biosensors and Bioelectronics. 2019;128: 17-22.

57. Enomoto $\mathrm{Y}$, Yoshikawa T, Ihira M, Akimoto S, Miyake F, Asano $\mathrm{Y}$, et al. Rapid diagnosis of herpes simplex virus infection by a loop-mediated isothermal amplification method. Journal of Clinical Microbiology. 2005;43(2):951-955.

58. Rödel J, Bohnert JA, Stoll S, Wassill L, Edel B, Pfister W, et al. Evaluation of loopmediated isothermal amplification for the rapid identification of bacteria and resistance determinants in positive blood cultures. European Journal of Clinical Microbiology \& Infectious Diseases. 2017; 36(6):1033-1040.

59. Yeh HY, Shoemaker CA, Klesius PH. Evaluation of a loop-mediated isothermal amplification method for rapid detection of channel catfish Ictalurus punctatus important bacterial pathogen Edwardsiella ictaluri. Journal of microbiological methods, 2005;63(1):36-44.

60. Mamba TS, Mbae CK, Kinyua J, Mulinge E, Mburugu GN, Njiru ZK. Lateral flow loop-mediated isothermal amplification test with stem primers: Detection of cryptosporidium species in Kenyan children presenting with diarrhea. Journal of Tropical Medicine; 2018.

61. Tambo M, Auala JR, Sturrock HJ, Kleinschmidt I, Bock R, Mumbengegwi DR, et al. Evaluation of loop-mediated isothermal amplification as a surveillance tool for malaria in reactive case detection moving towards elimination. Malaria Journal. 2008;17(1):255.

62. Modak SS, Barber CA, Geva E, Abrams WR, Malamud D, Ongagna YSY. Rapid point-of-care isothermal amplification assay for the detection of malaria without nucleic acid purification. Infectious Diseases: Research and Treatment. 2016; 9.

IDRT-S32162.

63. Tomlinson J. In-field diagnostics using loop-mediated isothermal amplification. In Phytoplasma. 2013;291-300. Humana Press, Totowa, NJ.

64. Sirichaisinthop J, Buates S, Watanabe R, Han ET, Suktawonjaroenpon W, Krasaesub S, Sattabongkot J, et al. Evaluation of Loop-Mediated Isothermal Amplification (LAMP) for malaria diagnosis in a field setting. The American Journal of Tropical Medicine and Hygiene. 2011; 85(4):594-596.

65. Poon LL, Wong BW, Ma EH, Chan KH, Chow LM, Peiris JM, et al. Sensitive and inexpensive molecular test for falciparum malaria: detecting Plasmodium falciparum DNA directly from heat-treated blood by loop-media ted isothermal amplification. Clinical Chemistry. 2006;52(2):303-306.

66. Cook J, Aydin-Schmidt B, González IJ, Bell $D$, Edlund E, Bjork Man A, et al. LoopMediated Isothermal Amplification (LAMP) for point-of-care detection of asymptomatic low-density malaria parasite carriers in Zanzibar. Malaria Journal. 2015; 14(1):43.

(C) 2019 Uwiringiyeyezu et al.; This is an Open Access article distributed under the terms of the Creative Commons Attribution License (http://creativecommons.org/licenses/by/4.0), which permits unrestricted use, distribution, and reproduction in any medium, provided the original work is properly cited.

The peer review history for this paper can be accessed here: http://www.sdiarticle3.com/review-history/50826 